\title{
Belphégor
}

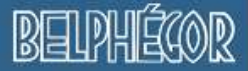

Littérature populaire et culture médiatique

15-1 | 2017

1936: les Jeux olympiques dans la presse

internationale

\section{Bibliographie générale}

\section{(2) OpenEdition}

Journals

Electronic version

URL: http://journals.openedition.org/belphegor/850

DOI: $10.4000 /$ belphegor.850

ISSN: 1499-7185

Publisher

LPCM

Electronic reference

«Bibliographie générale », Belphégor [Online], 15-1 | 2017, Online since 17 April 2017, connection on 03 May 2019. URL : http://journals.openedition.org/belphegor/850 ; DOI : 10.4000/belphegor.850

This text was automatically generated on 3 May 2019.

\section{(c) (i) (9)}

Belphégor est mis à disposition selon les termes de la Licence Creative Commons Attribution - Pas d'Utilisation Commerciale - Pas de Modification 4.0 International. 


\section{Bibliographie générale}

\section{Travaux sur le contexte historique, l'histoire du sport et des Jeux olympiques de Berlin}

1 ABGRALL, Fabrice et THOMAZEAU, François, La France à l'épreuve des Jeux Olympiques de Berlin, Paris, Alvik éditions, 2006.

2 AUGER, Fabrice, Une Histoire politique du mouvement olympique: l'exemple de l'entre-deuxguerres, Thèse pour le doctorat d'histoire contemporaine, Université Paris X-Nanterre, 1998.

3 BANCEL, Nicolas, Du guerrier à l'athlète : éléments d'histoire des pratiques corporelles, Paris, PUF, 2002.

4 Bellanger, Cl., GODECHOT, J., GUIRAL, P. \& TERROU, F., Histoire générale de la presse française, tome 3 : 1871-1940, Paris, PUF, 1972.

5 BENOUSSAN, Georges, DIETSCHY, Paul, FRANÇOIS, Caroline \& STROUK, Hubert, Sports, corps et sociétés de masse : le projet d'un homme nouveau, Paris, Armand Colin, 2012. BLAIZEAU, Jean-Marie, Les Jeux défigurés, Paris, Les Indes Savantes, 2012.

7 BoLI, Claude (dir.), Les Jeux Olympiques. Fierté nationale et enjeu mondial, Biarritz, Atlantica, 2008, pp. 117-124.

8 BOLZ, Daphné, Les arènes totalitaires : fascisme, nazisme et propagande sportive : Hitler, Mussolini et les jeux du stade, Paris, CNRS éditions, 2008.

9 Bolz, Daphné, "L'événement en histoire culturelle du sport: essai d'historiographie ». In : Movement \& Sport Sciences $n^{\circ} 86,2014$, pp. 81-91, disponible sur cairn.info.

10 BOURDIEU, Pierre, «Les Jeux olympiques : programme pour une analyse ». In : Actes de la recherche en sciences sociales, vol. 103, 1994, pp. 102-103, disponible sur Persée.

11 BRoнM, Jean-Marie, 1936. Jeux olympiques à Berlin, Éditions Complexe, « La mémoire du siècle », 1983.

12 CLASTRES, Patrick \& DIETSCHY Paul, Sport, culture et société en France du XIXe siècle à nos jours, Paris, Hachette Supérieur, 2006. 
CLASTRES, Patrick \& MEADEL, Cécile, «Quelle fabrique du sport? Quelques éléments introductifs ». In : Le Temps des médias n 9, 2007, pp. 6-18, disponible sur cairn.info.

DAUNCEY, Hugh, " Entre presse et spectacle sportif, l'itinéraire pionnier de Pierre Giffard (1853-1922) ». In : Le Temps des médias n 9, 2007, pp. 35-46, disponible sur cairn.info.

DEFRANCE, Jacques, «L'autonomisation du champ sportif : 1890-1970 ». In : Sociologie et sociétés, vol. 27, $\mathrm{n}^{\circ} 1,1995$, pp. 15-31, disponible sur erudit.org.

DERLON, Alain, Sport, nationalisme français et régénération de la "race »: 1880-1914, Paris, L'Harmattan, 2008.

HART-DAVIS, Duff, Hitler's Games : The 1936 Olympics, London, Century Hutchinson, 1986.

FAVRE, Christian, La Suisse face aux Jeux Olympiques de Berlin 1936. Un pays partagé entre la contestation et la sauvegarde de ses intérêts avec le IIIe Reich, Université de Fribourg, 2004.

GEBAUER, Günter et WULF, Christoph, «Les jeux de la violence ». In : Actes de la recherche en sciences sociales, vol. 79, « L'espace des sports-1», 1989, p. 63-75, disponible sur Persée.

GRITTI, Jules, Sport à la une, Paris, Armand Colin, 1973.

GUILBERT, Laure, Danser avec le IIIe Reich, les danseurs modernes et le nazisme, Bruxelles, Complexe, 2000.

KRÜGER, Arnd \& MURRAY, William (eds.), The Nazi Olympics. Sport, Politics and Appeasement in the 1930s. Champaign, University of Illinois Press, 2003.

GUIDO, Laurent et alii (dir.), La mise en scène du corps sportif, Lausanne, Musée olympique, 2002.

LAGRUE, Pierre, "Les Jeux nazis: propagande, complicité, naïveté », dans Le Siècle olympique. Les Jeux et l'Histoire (Athènes, 1896 - Londres, 2012), Encyclopaedia Universalis, 2013 [édition électronique].

LARGE, David Clay, « The Nazi Olympics : Berlin 1936 », in Helen Jefferson Lenskyj, Stephen Wagg (dir.) The Palgrave Handbook of Olympic Studies, New York, Palgrave Macmillan, 2012.

LERCH, Lionel, Le livre des J.O.B. Les Jeux Olympiques de Berlin dans la presse française, Mém. Maîtrise Histoire contemporaine, U. Lyon 2, dir. : Y. Lequin. (Centre Pierre Léon), 1998.

MICHAUD, Éric, Un art de l'éternité. L'image et le temps du national-socialisme, Paris, Gallimard, 1996.

MILZA, Pierre, « Sport, guerre et politique : la face noire des J.O. ». In : Histoire n $^{\circ}$ 199, 1996.

PERRAKI, Vivi, « Entrée du sport dans les titres de presse ». In : Mots n²9, 1991, pp. 93-98, disponible sur Persée.

ROCHE, Maurice, Mega-Events and Modernity: Olympics and Expos in the Growth of Global Culture, London, Routledge, 2000.

SCHMIDT, Josef, «Événement fasciste et spectacle mondial : les Jeux olympiques de Berlin en 1936 ", dans Régine ROBIN (dir.), Masses et culture de masse dans les années 30, Paris, Éditions ouvrières, « mouvement social », 1991, p. 163-179.

SEIDLER, Edouard, Le sport et la presse, Paris, Armand Colin, 1964.

SOMBREFFE, Jean-Christian, « La participation de la Belgique aux Jeux olympiques de Berlin en 1936 ». In : Revue belge d'histoire contemporaine, vol. 3-4, 1998, p. 405-443.

TETART, Philippe (dir.), Histoire du sport en France du second Empire au régime de Vichy, Paris, Vuibert, 2007. 
WASER, Anne-Marie (2000). "L'internationalisation du sport. Transformation d'une entreprise universelle en un organisme au service des intérêts particuliers: le comité international olympique (1894-1925) ». In: Regards Sociologiques, $\mathrm{n}^{\circ}$ 20, pp. 5-25, disponible sur regards-sociologiques.com.

\section{Travaux sur l'histoire de la presse et de ses pratiques}

ARON, Paul et GÉMIS, Vanessa (éd.), «Entre journalisme et littérature, l'institution du reportage ». In : COnTEXTES [En ligne], $\mathrm{n}^{\circ} 11 \mid 2012$

BOLLINGER, Ernest La presse suisse : structure et diversité, Berne, H. Lang ; Francfort/M : P. Lang, 1976.

BOUCHARENC, Myriam, "Choses vues, choses lues: le reportage à l'épreuve de l'intertexte ». In : Cahiers de Narratologie [En ligne], 13 | 2006, mis en ligne le 01 septembre 2006. URL : http://narratologie.revues.org/320)

BOUCHARENC, Myriam, L'écrivain-reporter au cœur des années trente, Villeneuve d'Ascq, Presses universitaires du Septentrion, 2004.

CAMBRon, Micheline, "De l'importance de la facture des périodiques dans la compréhension de l'histoire de la littérature du Bas-Canada ». In: Fac-Simile, n ${ }^{\circ} 14$, novembre 1995, p. 12-15 CAMBRON, Micheline (dir.), Le Journal Le Canadien. Littérature, espace public et utopie (1836-1845) (dir.), Montréal, Fides, coll. «Nouvelles études québécoises », 1999.

DELPORTE, Christian, «Les journalistes dans l'entre-deux-guerres, une identité en crise ». In : Vingtième Siècle. Revue d'histoire nº 47, 1995, pp. 158-175, disponible sur Persée.

FRIzOT, Michel et VEIGY, Cédric de, Vu. Le magazine photographique, 1928-1940, Paris, Éditions de La Martinière, 2009.

HAVER, Gianni, « La presse illustrée en Suisse, 1893-1945 », in Gianni Haver (dir.), Photo de presse, Lausanne, Antipodes, 2009, pp. 39-65.

HEINICH, Nathalie, De la visibilité, Excellence et singularité en régime médiatique, Gallimard, 2012.

KALIFA, Dominique, RÉGNIER, Philippe, THÉREnTY, Marie-Ève et VAILlant, Alain (dir.), La civilisation du journal. Histoire culturelle et littéraire de la presse française au XIXe siècle, Paris, Nouveau monde éditions, 2011.

LEENAERTS, Danielle, Petite histoire du magazine $V u$ (1928-1940). Entre photographie d'information et photographie d'art, Bruxelles, P.I.E. Peter Lang, 2010.

MANevy, Raymond, La Presse de la IIIe République, Paris : J. Foret, 1955.

MiLle Hervé, Cinquante ans de presse parisienne, Paris : La Table ronde, 1992.

POURQUERY, Didier et LABARDE, Philippe, Paris-Soir. France-Soir. La photo à la une, Paris, Paris musées, 2006.

SOUCHIER, Emmanuël « Formes et pouvoirs de l'énonciation éditoriale ». In : Communication et langages. $\mathrm{N}^{\circ} 154,2007$, p. 23-38.

SOUCHIER, Emmanuël (dir.), "L'énonciation éditoriale en question », numéro spécial de Communication \& langages, $\mathrm{n}^{\circ} 154$, décembre 2007, p. 23-121 et 135-138.

Belphégor, 15-1 | 2017 
52 SOUCHIER, Emmanuël, «L'image du texte pour une théorie de l'énonciation éditoriale ». In : Les cahiers de médiologie, 1998/2 N6, p. 137-145. En ligne: http://www.cairn.info/ revue-les-cahiers-de-mediologie-1998-2-page-137.htm

53 TARDIVON, Jean-Christophe, La Photographie politique médiatisée : entre actualité et histoire. Étude de cas dans la presse française du début des années 1930, mémoire du D.E.A. en sciences du langage, EHESS, 1999.

54 THÉRENTY, Marie-Ève et VAILLANT, Alain, L'an un de l'ère médiatique. Analyse liittéraire et historique de La Presse de Girardin, Paris, Nouveau monde éditions, 2001. THÉRENTY, Marie-Ève, « Pour une poétique historique du support ». In : Romantisme, 2009/1 $\mathrm{n}^{\circ} 143$, p.109-115. En ligne: http://www.cairn.info/revue-romantisme-2009-1page-109.htm; THÉRENTY, Marie-Ève, «Poétique historique du support et énonciation éditoriale : la case feuilleton au XIX ${ }^{\mathrm{e}}$ siècle ». In : Communication \& langages, 2010, pp 3-19. En ligne : http://necplus.eu/abstract_S0336150010014018 THÉRENTY, Marie-Ève, La Littérature au quotidien: poétiques journalistiques au XIXe siècle, Paris, Seuil, 2007. 